\title{
Visualization and virtual screening in molecular property spaces
}

\author{
A Klenner, ${ }^{*}$ M Reutlinger, G Schneider \\ From 6th German Conference on Chemoinformatics, GCC 2010 \\ Goslar, Germany. 7-9 November 2010
}

For virtual screening and similarity searching numerous descriptors can be employed to represent molecular structures and properties. Concurrently these descriptors always create a chemical property space. Typically, we lack information on how these spaces are structured and organized due to their high dimensionality. We present a projection method that allows for the visualization of such property spaces of large databases while maintaining the high-dimensional spatial structures and neighbourhood behaviour (Figure 1). The process of visualisation can help us understand how descriptors 'perceive' molecules and can give surprising insights which molecules are actually considered to be similar in these spaces. Furthermore we implemented a clustering algorithm using convex hulls for separating arbitrary molecule classes and automated feature extraction algorithm for identifying space defining features.

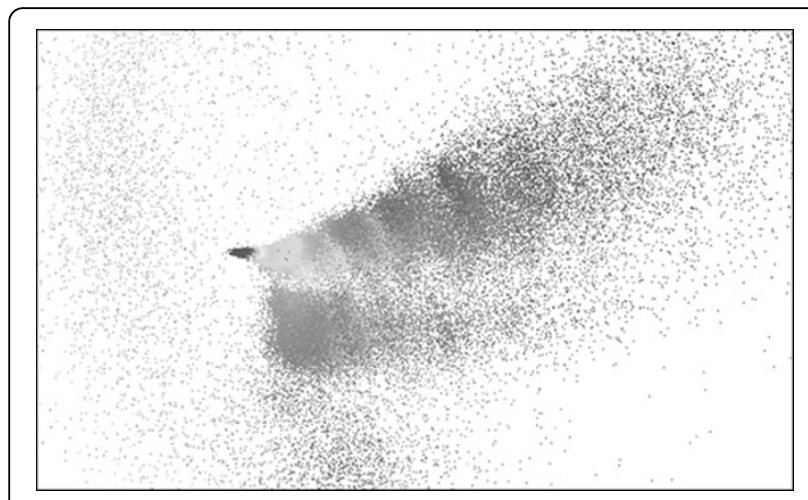

Figure 1 Projected property space of $\sim 200.000$ compounds from 90 dimensional space.

* Correspondence: alexander.klenner@pharma.ethz.ch

Institute of Pharmaceutical Sciences, ETH, Zurich, 8048, Switzerland
Published: 19 April 2011

doi:10.1186/1758-2946-3-S1-P8

Cite this article as: Klenner et al: Visualization and virtual screening in molecular property spaces. Journal of Cheminformatics 2011 3(Suppl 1):P8.

\section{Publish with ChemistryCentral and every scientist can read your work free of charge \\ "Open access provides opportunities to our colleagues in other parts of the globe, by allowing anyone to view the content free of charge." \\ W. Jeffery Hurst, The Hershey Company.}

- available free of charge to the entire scientific community

- peer reviewed and published immediately upon acceptance

- cited in PubMed and archived on PubMed Central

- yours - you keep the copyright

Submit your manuscript here:

http://www.chemistrycentral.com/manuscript/ 